\title{
Sensación y Política en Gilles Deleuze
}

\author{
Sensation and politics in Gilles Deleuze
}

\section{Ricardo Espinoza Lolas, Patricio Lombardo Bertolini, Camilo Valdes Castillo*}

Pontificia Universidad Católica de Valparaíso, Valparaíso, Chile

\section{Resumen}

Este artículo interroga por la fina y precisa relación entre Arte y Política al interior del pensamiento del filósofo francés Gilles Deleuze (1925-1995). Se intenta mostrar cómo Deleuze, en parte siguiendo el trabajo inacabado y juvenil de Nietzsche, quiere realizar una filosofía política desde una lógica de la sensación. Y no como los hegelianos o marxianos o marxistas, etc. que siempre han pensado lo político desde una lógica negativa de la dialéctica histórica. El plan de Deleuze, fundamentalmente en su última etapa, en su trabajo en torno al arte, en general, y, en especial, con la pintura versa desde una lógica de la sensación. Y es desde esta lógica dónde se da el lugar que expresa lo político.

Palabras-clave: Deleuze. Cézanne. Sensación. Pintura. Política.

REL: Doctor en Filosofía, e-mail: ricardo.espinoza@pucv.cl

PLB: Doctor en Filosofía, e-mail: patricio.lombardo@pucv.cl

CVC: Licenciado en Filosofía, e-mail: camilovaldes.11@gmail.com 


\section{Abstract}

This article questions the fine and precise relationship between art and politics into the thought of the French philosopher Gilles Deleuze (1925-1995). It tries to show how Deleuze, partly following the unfinished work and youthful Nietzsche, wants to make a political philosophy give yourself a logic of sensation. And not like the Hegelian or Marxian or Marxist, etc. who have always thought politics from a negative logic of the historical dialectic. The plan Deleuze, mainly in its last stage, in his work on art in general and, in particular, with painting versa from a logic of sensation. And it is from this logic that expresses the place where politics is given.

Keywords: Deleuze. Cézanne. Sensation. Painting. Politics.

\section{Introducción}

Sensación y política en Gilles Deleuze es un intento de repensar lo que siempre hemos visto y pensado en torno a lo más propio del pensamiento del filósofo francés, que a su vez creemos que es como él mismo lo vio respecto de su "maestro" Nietzsche (DELEUZE, 2000; DELEUZE, 2002); esto es, una filosofía eminentemente política, pero no establecida desde Hegel. Es decir, no pensada desde la negatividad del concepto y menos de un concepto que se piensa dialécticamente en Aufhebung (cancelación-elevación); sino una política agenciada desde el devenir animal, desde el cuerpo, desde el deseo, desde, en definitiva, la sensación. Y para esto el arte es de suma importancia para Deleuze. En el arte radicalmente se juega el trabajo de la sensación. Y aquí está la base de lo político.

Lo político en Deleuze es fundamental y gravitante en su obra (y cada vez más al final de ella); y a veces se cubre con todo su trabajo en torno al arte. Su obra versa esencialmente sobre lo político aunque no tenga una obra explícita dedicada al tema. Y esto igual a Nietzsche, que solamente encontramos ideas por allí y por ahí en su laberíntica obra relacionada explícitamente sobre lo político. Y en Deleuze esto es así y no podría ser de otra manera. Porque lo político acontece en 
especial en el ámbito del arte como en Nietzsche (LOLAS, 2012, p. 224225. LOLAS, 2004, p. 71-88). Y sobre arte Deleuze sí escribió mucho además de dar cursos y conferencias sobre el tema.

Nos atrevemos a indicar que toda su obra en torno al arte: pintura, música, literatura, cine, etc. tienen expresión política. Pues es el arte el lugar de lo político en Deleuze (como en Nietzsche) (LOLAS, 2008, p. 193-229). Pero el arte se articula en juego con la sensación, con una lógica del sensación y, por ende, antes de hablar de lo político necesitamos recordar lo que expresa la sensación. La política descansa en el arte y éste en la sensación.

\section{La filosofía de Deleuze}

Un problema que tenemos con la filosofía de Deleuze es que su obra, que es extensa en lo material, es en sí misma fragmentaria en lo cualitativo, una "meseta", un "pliegue" diría él:

“Es interesante señalar que la descripción del Barroco como un pliegue que va al infinito es, en cierta forma, la concepción misma del pliegue y de la filosofía de Leibniz en tanto filosofía de mónadas; pero también es el rasgo singular y propio de los conceptos y es lo propio de la filosofía de Deleuze" (LOLAS, 2009, p. 131).

Y por lo mismo podemos encontrar distintos modos de decir lo mismo, o distintos modos de hacer sonar eso que se llama cuerpo, sensación, etc. a lo largo de distintos libros-experiencia de Gilles Deleuze: Lógica del sentido, Diferencia y repetición, El Anti-Edipo, Mil Mesetas, La Imagen-Movimiento, La Imagen-Tiempo, El Pliegue. Leibniz y el Barroco, ¿Qué es filosofía?, etc. y también nos encontramos con sus estudios monográficos sobre: Hume, Leibniz, Spinoza, Kant, Nietzsche, Proust, Foucault, etc.

$Y$ además es una obra que piensa distintos temas articulados entre sí: filosofía, física, literatura, pintura, cine, psicología, etc. y al parecer nunca lo político. Se pretende por el investigador buscar lo político en el pensamiento de Deleuze en algún lugar determinado de 
sus textos, en un pasaje, en una entrevista, en una referencia explícita, en un comentario, en algún concepto determinado (como por ejemplo, "sociedades de control"), etc., empero siempre son pinceladas; aunque profundas pero pinceladas en comparación con otros filósofos actuales que tienen libros completos sobre el tema político (Rancière, Zizek, Badiou, etc.). La obra de Deleuze, como nos damos cuenta, es enorme y se sigue editando y trabajando en torno a ella (se publican sus conferencias, artículos, entrevistas, cursos, etc.); en donde podemos ver que cada libro es siempre una experiencia, un devenir del tema hecho materia, hecho imagen, hecho cuerpo, pero como un "cuerpo sin órganos". Un cuerpo que no se deja transcribir, ni traducir, ni cazar, en ningún tipo de negatividad, de dialéctica, de lógica apofántica, de estructuración, de representación, de archivo, etc. Para Deleuze la filosofía en tanto estructuración en negatividad (entendida como dialéctica) ya del tipo hegeliana, ya marxiana, marxista, postmarxista, estructuralista, psicoanalítica, etc. no pueden expresar el devenir mismo del cuerpo. El problema de la expresión de la filosofía, del lenguaje de ella es un tema muy importante en Deleuze (LOLAS, 2006, p. 77-99).

Nosotros pensamos que en el gran desarrollo del arte por parte de Deleuze y en especial al final de su vida podemos encontrar todos los elementos necesarios para reconstruir una "lógica de la sensación política". Es una lógica que se basa en una historia natural de la sensación que nos permite pensar lo plenamente político desde lo más propio humano, su devenir animal (LOLAS, 2012, p. 155-175).

\section{En torno al cuerpo y Artaud}

Deleuze siempre filosofa de un modo radical y contra corriente a lo usual de otras filosofías; su metodología no es ni de las clásicas ni de las actuales, o sea, no es, dicho con simplicidad, ni estructuralista ni post-estructuralista. Su pensamiento intenta, siguiendo a Nietzsche, pensar de otro modo o, mejor dicho, pensar desde otro órgano, no desde la cabeza, por decirlo de alguna manera, sino desde el cuerpo mismo; se trata de pensar el cuerpo desde un "prius" (ZUBIRI, 1980) en 
anterioridad con respecto de estructuraciones, relatos, rostros, narraciones, teorías, etc.:

Aquí nos interesa ese vértice... anterior a cualquier representación', a cualquier 'organización' o 'figuración' de lo que sea el cuerpo, pero no cualquier cuerpo sino el cuerpo humano; se trata de pensar el cuerpo desde un 'prius' en dominancia con respecto de figuraciones, relatos, rostros, narraciones, teorías, hermenéuticas, etc. (ALVARADO; LOLAS; LANDAETA, 2014, p. 414).

Es lo que Deleuze llama radicalmente, siguiendo a Artaud, un "cuerpo sin órganos". La cita típica de esto es:

Las máquinas deseantes no forman un organismo; pero en el seno de esta producción, en su producción misma, el cuerpo sufre por ser organizado de este modo, por no tener otra organización, o por no tener ninguna organización. 'Una parada incomprensible y por completo recta' en medio del proceso, como tercer tiempo: 'Ni boca. Ni lengua. $\mathrm{Ni}$ dientes. Ni laringe. Ni esófago. Ni vientre. Ni ano'. Los autómatas se detienen y dejan subir la masa inorganizada que articulaban. El cuerpo lleno sin órganos es lo improductivo, lo estéril, lo engendrado, lo inconsumible. Antonin Artaud lo descubrió, allí donde estaba, sin forma y sin rostro (DELEUZE, 1985, p. 6).

Anterior al rostro, a la figuración, a la narración, a la presencia, a la institución, a la urbanización (LANDAETA; LOLAS, 2014, p. 295315) tenemos ese hecho radical que fluye inexorablemente: el devenir del cuerpo; aquí tenemos ya el primordio mismo de lo político para Deleuze; en ese devenir mismo del cuerpo, un devenir anterior a cualquier rostro representativo concreto político. Lo que se trata es que anterior a la política y sus estructuraciones institucionales, ideológicas e históricas, tenemos algo anterior y físico en el cuerpo mismo que mienta luego cualquier posibilidad de estructuración (LOLAS, 2009a, p. 225-250). ¿Qué es eso anterior y que decimos que es lo propiamente político y anterior a las políticas? ¿Cómo eso animal sería lo más radicalmente político?

Tratemos de quedarnos, para entender acabadamente nuestra interpretación, en esto que hemos citado y memorizado mil veces. 
Y pensar plenamente lo de Artaud en la siguiente sentencia: "Ni boca. Ni lengua. Ni dientes. Ni laringe. Ni esófago. Ni vientre. Ni ano". ¿Qué significa semejante expresión; esta cadena de expresión? Si nos damos cuenta de eso se trata, es decir, de los órganos que dan de sí al cuerpo; tal como lo vemos siempre desde nuestra mirada ideologizada y ontologizada desde los inicios de nuestras vidas, desde los inicios de nuestra sociedad, de nuestra historia, ya nuestra como la de todos. Es un pensamiento ideologizado y que pretende ontologizar al hombre y con ello la realidad queda sustancializada desde la organización, la estructuración. Es la ideología que siempre quiere pasar por ontología que indica que se da de entrada una estructuración de base. Hombre y mundo ideologizado desde una cierta organización ya metafísica, ya teológica, ya científica, ya tecnológica, ya fenomenológica, ya hermenéutica, ya gramatológica, etc. Deleuze era muy crítico de Derrida (DELEUZE, 1985, p. 167). En la cadena de órganos que describe Artaud y que a la vez va negando, una cierta dialéctica sin Aufhebung, porque va diseminado lo que describe, mejor dicho, va borrando lo que instala. La obra de Artaud es como lo que hace luego John Cage o Tunga (TUNGA, 2001, p. 120-122), esto es, una instalación en la inmanencia misma de la textura material y allí acontece tal materialidad propiamente tal.

Intentemos ver la simple pero brillante idea de esta instalación material que nos hace Artaud a través de su célebre texto; celebridad que se le debe a Deleuze. Boca, esto es, "No boca"; lengua, esto es, "No Lengua"; diente, esto es, "No diente"... ano, esto es, "No ano". En esa tensión improductiva (a lo Bataille), sin negación determinada, por ende, sin ninguna mediación posible lo que queda es simplemente la borradura del órgano; su gesto. Y esto es fundamental. Así como los cepillados de los rostros de Bacon o las borrosidades de los recuerdos de Proust. Y en esa borradura de lo que es, va quedando como estancias materiales; deseos. Lo que queda son borraduras.

Es decir, como una cierta "mancha" (no olvidemos los cuadros de Bacon, tan estudiado por Deleuze), la que por una parte indica radicalmente materialidad y por otra señala negación de organización inicial de entrada y por ende una eliminación total de la posibilidad de 
cualquier ontología (contra Platón y la historia clásica de la filosofía). En el fondo el materialismo en su carácter más físico y radical; lo mejor del atomismo antiguo (DELEUZE, 1994). Y que indica esa tensión de lo improductivo, de lo no ontológico, sino de lo material mismo en Artaud. Lo propio del hombre antes de ser construido por la ideología institucional del cristianismo y la modernidad europea, esto es, un acontecimiento somático; una fuga que se expresa desde orificio de la boca al orificio del ano. El cuerpo se fuga por el orificio (es cosa de pensar en la serie de los papas de Bacon); el cuerpo acontece en el orificio in actu exercito. Fuga (DELEUZE, 1995), orificio, poro, expresa la salida por excelencia. Es el éxtasis lo propio del cuerpo y esto se muestra en la categoría de cuerpo sin órganos, mejor dicho en nietzscheano, del mítico dios Dionysos de los griegos (LOLAS; ASCORRA; VARGAS, 2012, p. 95-116). Lo que indica Artaud, en su lenguaje brutal, es la expresión misma del dios griego y tan caro a Nietzsche. Por eso es la ausencia de forma, de rostro; es Dionysos en el acto mismo de su expresión, anterior a su apolonización. De allí su oscuridad, su esterilidad, su improductividad; deseo, nada más que deseo. Un deseo que no sirve para nada porque no hay metafísica y en ello ética alguna que lo alcance (aquí resuena obviamente Spinoza). Pura circularidad que nunca se consuma porque nunca se agota y siempre está ahí dando de sí cerrado sobre sí mismo, en la noche misma de su desierto (LOLAS; ASCORRA; LANDAETA; SOTO, 2014, p. 237-248). Y en esa circularidad, vuelve, vuelve, vuelve jovialmente y constituye todo día en su claridad como en su oscuridad. El deseo, nunca goce ni placer (contra Foucault), pero Deseo con mayúscula. No solamente lo ha expresado brillantemente Nietzsche, sino que el mismo Cavafis lo ha dicho mejor que nadie...

\section{El poeta lo decía así:}

Retorna a menudo y tómame, / amada sensación, retorna y tómame- / cuando despierta la memoria del cuerpo, / y un viejo deseo vuelve a fluir por la sangre; / cuando los labios y la piel recuerdan, / y las manos se sienten como acariciando de nuevo[...]Retorna a menudo y tómame en la noche, / cuando los labios y la piel recuerdan... (CAVAFIS, 1991, p. 83). 
De eso se trata. Estamos en la sensación. Artaud nombra la sensación con todo en su gesto de instalar y borrar y en ello expresar al hombre como mancha, deseo; en ello lo que expresa es la mera sensación. Somos el acontecimiento, esto es, la sensación por excelencia.

\section{Pintura y sensación}

Para indicar ese carácter físico de la sensación, en esta "lógica rizomática" Gilles Deleuze acude al arte, en general, y a la pintura, en especial (como sabemos quería dedicarse a la pintura al final de su vida), y más precisamente a estudiar con detención y profundidad cuadros del Greco, de Klee, de Van Gogh, de Bacon o Cézanne muy especialmente entre otros pintores. Deleuze dice en fórmula sintética respecto de la pintura: "La pintura debe arrancar la Figura de lo figurativo" (DELEUZE, 2005, p. 26). ¿Cómo se da esto? ¿Cómo pintar la sensación? ¿Cómo pintar la sensación de la manzana antes de cualquier representación ideologizada de la misma? ¿Cómo pintar un No Rostro, una No Manzana? ¿Cómo pintar el acontecimiento de la sensación? ¿Cómo pintar la política? ¿Cómo dar con una política no representacional, sino del cuerpo sin órganos, del deseo, de la sensación? Si la política se asocia al Estado, ¿Es posible una No política? ¿Es posible la sensación de lo político? Esto es lo que anda buscando Toni Negri en la actualidad (NEGRI; HARDT, 2004) y lo anda buscando como el loco que a pleno mediodía llegaba a las plazas con una linterna encendida, parafraseando a Nietzsche (NIETZSCHE, 2001). Y a veces al parecer lo está consiguiendo.

En la ontología representacional, en la articulación de significantes, en el horizonte de sentidos, es la Figura la que como "signo" nos deja la posibilidad, si es que queremos tomarla, en la sensación misma de "estar" corporalmente siendo. La Figura nos abre la posibilidad en el juego de su borrorosidad en su volver jovial que se desmantele toda metafísica de la esencia. Y en ello se libera sensación, soma, presencia, textura, estofas de la materia. Por detrás de las ontologías epocales e 
ideológicas se siente la Figura en su acontecer afirmativo en cuanto retornante y jovial. Deleuze lo dice de forma tajante así:

La pintura se propone directamente despejar las presencias que hay debajo de la representación. El propio sistema de los colores es un sistema de acción directa sobre el sistema nervioso... (DELEUZE, 2005, p. 28).

Deleuze lo expresa siempre en su estilo concreto, monádico de su lógica de la pintura y no podría realizarlo de otra forma, pues sería concederle al logos predicativo y la metafísica, en todas sus vertientes, un horizonte "óptico", de significación, un por fuera abstracto y omniabarcador, universalidad desde donde se aplica, se concreta, en cada caso: la dualidad de los mundos.

De allí que Deleuze siempre esté rompiendo la fenomenología desde dentro. Deleuze cercano a Merleau-Ponty, a la vez, se vuelve lejano de él (MERLEAU-PONTY, 2013) y lo destroza como animal, desde dentro de sí mismo, para romper ese rasgo universal y organizado que tiene la fenomenología para dar con la Figura, con el cuerpo, con la sensación. Y creemos que en esta bestial lucha lo que hay es siempre una postura política, más allá de mayo del 68. Un realizar lo imposible, esto es, realizar una política de la sensación en el carácter animal mismo del hombre antes de ser rostro e institución representativa. Una política del acontecimiento. Deleuze nos señala que para superar la figuración, la metáfora, le hermenéutica, el estructuralismo, el psicoanálisis o cualquier modo de representación o narración tenemos que pensar en términos de Figura, sensación y cuerpo. Y para esto la pintura de Cézanne (CEZANNE, 1991) es una genial indicadora de cómo esto se realiza:

Hay dos maneras de superar la figuración (es decir, a la vez lo ilustrativo y lo narrativo): o bien hacia la Forma abstracta, o bien hacia la Figura. A esta vía de la Figura Cézanne le da un nombre sencillo: la sensación. La Figura es la forma sensible relacionada con la sensación; actúa inmediatamente sobre el sistema nervioso, que es carne. Mientras que la Forma abstracta se dirige al cerebro, actúa por mediación del cerebro, más cercano al hueso (DELEUZE, 2005, p. 29). 
Texto brillante y magistral. Esto que parece muy difícil de comprender nos indica dos modos, por ejemplo, de hacer filosofía que no pretende ser ni fenomenología ni hermenéutica. Una la de Heidegger, la otra la de Deleuze (heredera de Nietzsche) (LOLAS, 2006, p. 45-65). La de Heidegger una filosofía cerebral desde la Forma abstracta y la deleuziana una filosofía del cuerpo, de la sensación desde la Figura. En Heidegger es cosa de pensar en sus gustos: budismo zen, pintura de Klee, poesía de Hölderlin, escultura de Chillida, pensamiento de Meister Eckhart, de Pascal, de Kant, de Kierkegaard, de Schelling, etc. y podemos entender su Ereignis (como la Forma abstracta por excelencia). Y en Deleuze sus gustos: matemática, física, música (LOLAS; ALVARADO, 2016), cine, pensamiento de Spinoza, de Nietzsche, de Bergson, etc. y podemos así entender su "Acontecimiento" (como la Figura).

\section{Política desde la sensación}

Tratemos de precisar brevemente un poco más lo que sea finalmente la "presencia", el "estar presente" y el logos de la sensación cobrará cuerpo, como un "cuerpo sin órganos". ¿Qué quiere decir esto de "estar presente"? Deleuze lo diría de esta forma y muy acertadamente: "presencia, presencia, es la primera palabra que llega ante un cuadro de Bacon" (DELEUZE, 2005, p. 31), que también llega por un cuadro de Velázquez o Van Gogh, y por un plano de Lynch o Godard, o un texto de Lewis Carroll o de Kafka, una pieza de Boulez o de Tavener (LOLAS; ALVARADO; LANDAETA, 2015, p. 203-213), etc. Las sensaciones, para Deleuze se recubren en el plano de inmanencia desde la Figura, el Sonido, la Imagen, el Trazo, etc.; se recubren en su carácter de materialidad misma aunque sean formalmente distintas (un olor, un color, un sonido, etc.). Esto es muy interesante de destacar y analizar. Deleuze como otros filósofos, como Zubiri, se han dado cuenta en su agudo y profundo análisis de la sensación que ésta no está dada de forma aislada y siempre se recubren entre si, aunque formalmente sean 
de sentidos distintos, ellas se recubren y esto acontece lo otro. Y a la vez lo que es propiamente el animal humano Las sensaciones se recubren:

Ante todo, los diversos sentidos no están meramente yuxtapuestos entre sí, sino que, por el contrario, se recubren total o parcialmente. Si se tratara del contenido cualitativo de cada sentir, este recubrimiento sería imposible. Sería absurdo pretender, por ejemplo, tener un sabor del fuego o de la estrella polar. Pero se trata de modos de presentación de lo real. Y estos modos, y no las cualidades. Son los que se recubren. Puedo tener perfecta intelección fruente de la estrella polar (ZUBIRI, 1980, p. 106-107).

En este recubrimiento modal y material se da la articulación de las cosas en tanto materiales y el hombre mismo en su articulación con las coas y con los otros hombres. Somos animales, manadas articuladas esencialmente los unos con los otros y con la naturaleza misma.

Tratemos de verlo en un detalle histórico, ya Wagner (tan querido por Deleuze) en su único Tristán e Isolda (estrenada en 1865 en München) indica de modo musical como en el libreto mismo, que en torno a la muerte, en el acontecimiento de lo real, se rompe toda metafísica construida para estructurar, disciplinar y organizar la sensación y en esto al hombre mismo. Y todas las sensaciones se liberan y vuelven a su jovialidad material e inmanente y así Tristán acontece y por eso él "escucha la luz" (WAGNER, 1999, p. 182). Tristán escucha la luz en el momento preciso, de su instante más propio y material: su muerte. En el instante de la muerte ante el amor total por su Isolda acontece la sensación, la naturaleza, el hombre, los hombres articulados los unos a los otros.

Presa de la más violenta y extrema exaltación, debatiéndose entre la vida y la muerte, recordando el resplandor de la antorcha y percibiendo en sus oídos el sonido de la voz de su amada, Tristán acaba por confundir el sentido de la vista con el del oído: Wie, hör ich dass Licht? Die Leuchte, ha! ('¿Cómo? ¿Oigo la luz? ¡La antorcha, ah! (Jacob, 1946, p. 288-289). 
Lo podríamos decir de otra manera, que más allá del análisis de la pintura que realiza Deleuze, lo que estamos indicando es aplicable a la sensación sin más; las sensaciones son más que analógicas, son digitales. Y esa digitalización está a la base para entender una política del acontecimiento, desde la sensación. Porque la representación se funda en la sensación y no al revés. Y esto es clave para entender todo el acontecimiento político de estos tiempos; acontecimiento que está socavando la política como representación:

La digitalización pone de manifiesto en términos matemáticos la matriz de sensaciones que informa y sustenta la representación. Esta matriz nunca es exclusivamente táctil u óptica sino más bien un híbrido: en la experiencia perceptiva real lo táctil-gestual y lo óptico-visual- supuestamente los modos de experiencia sensorial más primitivo y más sofisticado respectivamente- están codeterminados, por mucho que uno de ellos goce de mayor reconocimiento y de preferencia teórica (KUSPIT, 2006, p. 12).

Aunque la pintura se mueva en una expresión analógica de la sensación, la sensación misma en todas sus expresiones materiales y físicas están siendo vibraciones, intensidades, materializaciones que abren sentido y crean mundo. En esa sensación en tanto vibración intensa e inmanente articulando un cuerpo que se extiende podemos ir entendiendo cómo desde ese devenir es posible la construcción de otra política; de una política que no está solamente anclada al desarrollo histórico dialéctico del los grupos políticos que buscan representarnos.

Algo así piensa Gilles Deleuze cuando señala rotundamente:

Siendo espectador, no experimento la sensación sino entrando en el cuadro, accediendo a la unidad de lo sentiente y de lo sentido. La lección de Cézanne más allá de los impresionistas: la Sensación no está en el juego 'libre' o desencarnado de la luz y del color (impresiones), al contrario, está en el cuerpo, aunque fuere el cuerpo de una manzana. El color está en el cuerpo, la sensación está en el cuerpo, y no en los aires. Lo pintado es la sensación. Lo que está pintado en el cuadro es el cuerpo, no en tanto que se representa como objeto, sino que es vivido como experimentando tal sensación (DELEUZE, 2005, p. 38). 
Cézanne, el pintor francés por excelencia de Merleau-Ponty, se nos vuelve con sus célebres manzanas también en el pintor de Deleuze; Cézanne es el pintor de la sensación radicalmente. Porque ya no nos movemos en la ontología fenomenológica sino que ahora estamos en el cuerpo mismo, somos unos con lo sentido en lo sentido mismo que nos acontece. La sensación por eso no está en algún "aspecto" fenomenológico de descripción, sino en el cuerpo mismo, "es" el cuerpo mismo en tanto que acontece; es, por ejemplo, la manzana de Cézanne, el girasol de Van Gogh, la cabeza de Bacon, el nenúfar de Monet, el ángel de Klee, el vestido del Greco, etc. Se pinta la experiencia misma de la sensación en tanto acontecimiento. $\mathrm{Y}$ esto que hacen grandes pintores es lo que realizan grandes políticos como Lenin, Gramsci, Che Guevara, Pablo Iglesias, Alexis Tsipras. Ellos son políticos del acontecimientos, ellos expresan la sensación del cuerpo en un instante epocal dado. Y por eso pueden revertir la representación hegemónica histórico dialéctica. Esto es, ellos pueden realizar la revolución junto a sus equipos. Entre ellos vibran y agencian en el deseo y el cuerpo se expresa en toma de decisiones colectivas y la historia se recrea y vuelve y retorna. La historia acontece en diseños nuevos.

\section{Conclusión}

Para terminar, podemos dejar insinuado estas ideas de una política del acontecimiento. Deleuze dice de forma muy claramente en Proust y los signos que: "El pensamiento no es nada sin algo que fuerce a pensar, sin algo que lo violente. Mucho más importante que el pensamiento es 'lo que da a pensar'; mucho más importante que el filósofo, el poeta" (DELEUZE, PROUST, p. 41). Y la poesía como la de Cavafis es lo que mueve la filosofía, esto es, la sensación que retorna una y otra vez siempre de modo jovial, como lo señalaba ya Nietzsche en su Así habló Zaratustra (NIETZSCHE, 2000, p. 333-342). Lo podríamos decir de otra manera y siguiendo a los pintores. No se trata de "representar" manzana: "Ni manzana. Ni girasol. Ni cabeza. Ni nenúfar. Ni ángel. Ni vestido"; sino acontecimiento. 
¡He aquí el cuerpo! ¡He aquí la sensación! Deleuze lo diría perfectamente así:

La sensación es lo contrario de la fácil y lo acabado, del cliché, pero también de lo 'sensacional', de lo espontáneo... etc. La sensación tiene una cara vuelta hacia el sujeto (el sistema nervioso, el movimiento vital, el 'instinto', el 'temperamento', todo un vocabulario común al naturalismo y a Cézanne), y una cara vuelta hacia el objeto ('el hecho', el lugar, el acontecimiento). $\mathrm{O}$, más bien, no tiene del todo caras, es las dos cosas indisolublemente, es ser en el mundo, como dicen los fenomenólogos: a la vez devengo en la sensación y algo ocurre por la sensación, lo uno por lo otro, lo uno en lo otro. Y, en último término, el cuerpo mismo es quien la da y quien la recibe, quien a la vez es objeto y sujeto (DELEUZE, 2005, p. 42).

En el texto deleuziano resuena una vez más el pensamiento de Bergson, junto al de Nietzsche y Spinoza. Se trata de una lógica de la afección y en esta lógica has posibilidad para crear, esto es, crear una nueva Figura política. Una imagen que nos entiende como un cuerpo que vibra y agencia su desarrollo.

Luego realidad no es una cosa (y en esto es muy cercano a Lacan y por ahí hasta Zizek), no es una zona de realidad allende la aprehensión, no es una estructura a priori del sujeto pensante, no es una entidad $a$ posteriori de las cosas, no es ningún tipo de ente (ni el más excelso ni el más pobre); si lo queremos decir de forma tajante para evitar profundas confusiones, la realidad no es esencia del tipo que sea, ni tampoco es dios, ni menos alguna estructura básica de las que estudia la ciencia, ni el correlato de algo, ni las cosas en y por sí mismas, ni el fundamento, ni ningún tipo de modo de «organizar» los contenidos o cosas, etc., sino que es un "cuerpo sin órganos", deseo, nada más que deseo, esto es, sensación retornante. $\mathrm{Y}$ en tal sensación se abre corporalmente en su somática materialidad órdenes distintos, niveles, intensidades, comunidades, agrupaciones, colectivos, lo común entre todos nosotros. Eso que se resiste con todo a una organización. Porque obviamente que PODEMOS ya no es el $15 \mathrm{M}$. Ni el Gobierno de Tsipras es lo que fue SYRIZA. Ni lo que son esos jóvenes parlamentarios de partidos oficiales lo que fue el movimiento estudiantil. O sea, jugando a lo Artaud 
nuevamente: “Ni PODEMOS. Ni Gobierno de Tsipras. Ni jóvenes parlamentarios chilenos", sino "cuerpo sin órganos", sensaciones.

Deleuze es sumamente explícito en sus palabras y quedémonos con ellas para terminar con esta conferencia:

Cada sensación se da en diversos niveles, es de diferentes órdenes o está en varios dominios. De tal modo que no existen unas cuantas sensaciones de diferentes órdenes, sino diferentes órdenes de una única y la misma sensación. Pertenece a la sensación el desarrollar una diferencia constitutiva de nivel, una pluralidad de dominios constituyentes. Cualquier sensación, y cualquier Figura, ya es sensación 'acumulada', 'coagulada', como en una figura de caliza. De ahí procede el carácter irreductiblemente sintético de la sensación (DELEUZE, 2005, p. 43).

\section{Referencias}

CAVAFIS, C.P. Obra Completa. Madrid: La Palma, 1999.

CEZANNE, P. Correspondencia. Madrid: Antonio Machado, 1991.

DELEUZE, G. Francis Bacon. Lógica de la sensación. Madrid: Arena Libros, 2005.

DELEUZE, G. Proust e os signos. Río de Janeiro: Florense Universitaria, 2006.

DELEUZE, G. El Anti Edipo. Capitalismo y esquizofrenia. Barcelona: Paidós, 1985.

DELEUZE, G. Nietzsche. Madrid: Arena Libros, 2000.

DELEUZE, G. Nietzsche y la filosofía. Barcelona: Anagrama, 2002.

DELEUZE, G. Lógica del sentido. Barcelona: Paidós, 1994.

DELEUZE, G. Conversaciones. Valencia: Pre-Textos, 1995.

JACOB, W. Ricardo Wagner y su obra. Buenos Aires: Peuser, 1946.

KUSPIT, D. Arte digital y videoarte. Madrid: Círculo de Bellas Artes, 2006.

LANDAETA, P.; LOLAS, R. E. Geofilosofía de la ciudad para pensar más allá del organismo. Aurora, v. 26, n. 38, p. 295-315, 2014.

LOLAS, R. E. Nietzsche, intérprete de Platón. Hypnos, n. 25, p. 224-225, 2012. 
LOLAS, R. E. ¿Quién es Nietzsche? Hypnos, n. 12, p. 71-88, 2004.

LOLAS, R. E. Acerca de los 'Orígenes y Límites' del Lenguaje: El Mito de Babel y el Poema de Parménides. Cognitio, Volume 7, n. 1, p. 77-99, 2006.

LOLAS, R. E. Nietzsche e a Natureza que dança... In: Gazolla, R., (ed.), Cosmologias. Cinco ensaios sobre filosofia da naturaleza. San Pablo: Paulus. 2008. p. 193-229.

LOLAS, R. E. Deleuze: Leibniz en torno a los pliegues. Aurora, v. 21, n. 28, p. 125$139,2009$.

LOLAS, R. E. Repensando a Deleuze y el 'Acontecimiento' desde lo 'Lógico' de la Wissenschaft der Logik... en torno al devenir cosa. In: LOLAS, R. E. (ed.). Hegel. La transformación de los espacios sociales. Concón: Midas, 2012, p. 155-175.

LOLAS, R. E.; ALVARADO, B.; LANDAETA, P. La creación estética: sonido y vibración en John Tavener, Música Hodie, V. 15, N 2, p. 203-213, 2015.

LOLAS, R. E.; ALVARADO, B. Pierre Boulez-Gilles Deleuze: Ideas para una lógica de la sensación sonora. Kriterion, 2016.

LOLAS, R. E.; ASCORRA, P.; VARGAS, E. Nietzsche y la concepción de la Naturaleza como Cuerpo, Alpha, n. 34, p. 95-116, 2012.

LOLAS, R. E.; ASCORRA, P.; LANDAETA, P.; SOTO, P. Cuerpo y espacio. Reflexiones sobre una topología de la exterioridad. Filosofia Unisinos, v. 15, p. 237-248, 2014.

MERLEAU-PONTY, M. El ojo y el espíritu. Madrid: Trotta, 2013.

NEGRI, A.; HARDT, M. Multitud. Barcelona: Bebate, 2004.

NIETZSCHE, F. Así habló Zaratustra. Madrid: Alianza, 2000.

NIETZSCHE, F. La ciencia jovial. Madrid: Biblioteca Nueva, 2001.

TUNGA. Assalto. Brasilia: Centro Cultural, 2001

WAGNER, R. Richard Wagner. Obras escogidas. Barcelona: Edicomuniación, 1999. ZUBIRI, X. Inteligencia sentiente. Madrid: Alianza, 1980.

Recebido: 18/11/2016

Recibido: 11/18/2016

Aprovado: 17/01/2017

Aprobado: 01/17/2017 